Article

\title{
Modelling Daily Mean Surface Air Temperature Calculated from Different Methods and Its Impact on Urban-Related Warming Evaluations over Guangzhou and Shenzhen Using the WRF Model
}

\author{
Deming Zhao ${ }^{1, *}$ and Jian $\mathrm{Wu}^{2}$ \\ 1 CAS Key Laboratory of Regional Climate-Environment for Temperate East Asia, \\ Institute of Atmospheric Physics, Chinese Academy of Sciences, Beijing 100029, China \\ 2 Department of Atmospheric Science, Yunnan University, Kunming 650091, China; wujian@ynu.edu.cn \\ * Correspondence: zhaodm@tea.ac.cn
}

Received: 26 December 2018; Accepted: 21 January 2019; Published: 27 January 2019

\begin{abstract}
The impacts of urban surface expansion, based on satellite-derived data displaying urban surface expansion in China at different spatial scales from 1980 to 2016, were investigated using nested dynamical downscaling methods with the Weather Research and Forecasting (WRF) regional climate model at a $3.3-\mathrm{km}$ resolution over a city and city cluster scale. Urban-related warming, based on daily mean surface air temperature at $2 \mathrm{~m}$ (SAT), calculated from the averages of four time records each day $\left(00,06,12\right.$, and $\left.18 \mathrm{~h} \mathrm{UTC}, \mathrm{T}_{4}\right)$ and averages of SAT maximum $\left(\mathrm{T}_{\max }\right)$ and minimum $\left(\mathrm{T}_{\min }\right)\left(\mathrm{T}_{\mathrm{xn}}\right)$, was evaluated. Differences in urban-related warming contributions calculated using $T_{4}$ and $T_{x n}$ were small, whereas annual mean SAT and trends calculated using $\mathrm{T}_{\mathrm{xn}}$ were respectively and significantly larger and smaller than those calculated using $\mathrm{T}_{4}$ over Guangzhou and Shenzhen, excluding the trends over middle-northern Shenzhen. The differences in annual mean SAT calculated using $\mathrm{T}_{4}$ and $\mathrm{T}_{\mathrm{xn}}$ are attributed to nonlinear or asymmetric variations with time for the diurnal cycle of SAT. Meanwhile, differences in trends between $\mathrm{T}_{4}$ and $\mathrm{T}_{\mathrm{xn}}$ are interpreted as a strong trend for $\mathrm{T}_{\min }$ and a weak one for $T_{\max }$, which mitigated the trend for $\mathrm{T}_{\mathrm{xn}}$. The impacts on the evaluations of urban-related warming contributions calculated from different methods were the largest over the areas classified as urban surfaces in both time periods (U2U), especially during intense urban-surface-expansion periods between 2000 and 2016. The subregional performances in the changes in annual mean SAT, trends, and urban-related warming are attributed to urban-surface-expansion, which induced varied changes in the diurnal cycle due to asymmetric warming during the daytime and nighttime over different subregions.
\end{abstract}

Keywords: dynamical downscaling; surface air temperature; urban-related warming; trend; asymmetric warming

\section{Introduction}

Surface air temperature at $2 \mathrm{~m}$ (SAT) plays a primary role in the climatic systems, and has been widely regarded as an important climatic indictor in daily human life. The frequencies and intensities of extreme climatic events relating to SAT, such as heat waves and low temperatures that act as meteorological disasters and influence human health [1-3], have increased in recent decades. Increasingly more people are being aggregated in cities, where the urban heat island (UHI) has been widely observed over areas with intense urban surface expansion and human activities [4-6]. The UHI effect is primarily attributed to the conversion of land surfaces from non-urban to urban surfaces (N2U), for which the warming over the N2U areas is generally larger than that over areas classified as urban 
surfaces in both time periods (U2U) and areas with unchanged land use categories [7,8]. To objectively evaluate urban-related warming and the corresponding contributions to regional warming over different land surface characteristics, SAT, as a direct indicator, should be comprehensively observed and calculated.

However, despite the scarcity of the observed SAT and other meteorological observation records, such as the SAT maximum $\left(\mathrm{T}_{\max }\right)$ and minimum $\left(\mathrm{T}_{\min }\right)$ during the past several decades, the records for three time records each day $(00,06$, and $12 \mathrm{~h}$ UTC), four time records each day $(00,06,12$, and $18 \mathrm{~h}$ UTC), and continuous values within a 24 -h period, have been applied. The variation in the methods used to calculate daily mean SAT results in differences in the evaluated annual mean SAT and trends. Values calculated using the 24-h continuous records $\left(\mathrm{T}_{\mathrm{c}}\right)$ should represent the most direct and concise method for representing daily mean SAT [9]; however, the values calculated using the averages of SAT maximum and minimum records $\left(\mathrm{T}_{\mathrm{xn}}\right)$ [10], averages of three times each day, or averages of four times each day $\left(\mathrm{T}_{4}\right)$ [11], are usually adopted as the representative 'actual' values of daily mean SAT. This difference could impact the evaluations of urban-related warming and corresponding contributions to regional warming. Furthermore, the diurnal cycle of SAT displays nonlinear or asymmetric variations with time, which might induce SAT errors among the values calculated using $\mathrm{T}_{4}, \mathrm{~T}_{\mathrm{xn}}$, or $\mathrm{T}_{\mathrm{C}}$ [12]. Therefore, a comparison of the daily mean SAT calculated from various methods should be conducted, which can provide a basis for evaluating urban-related warming.

To quantitatively reveal the urban-related warming contributions calculated using $\mathrm{T}_{4}, \mathrm{~T}_{\mathrm{xn}}$, or $\mathrm{T}_{\mathrm{C}}$, a time series of observed-based SAT calculated using these methods is necessary. A long-term $T_{x n}$ time series might be available based on observed $\mathrm{T}_{\max }$ and $\mathrm{T}_{\min }[13,14]$; however, long-term $\mathrm{T}_{4}$ time series are less available because observation records with three times daily records were adopted for a certain period and then replaced by the four times daily observations [10]. Long-term $T_{c}$ time series are only available from when the automatic meteorological observation station appeared, which has only been adopted for the most recent decades. Therefore, comparing long-term SAT time series calculated using different methods is difficult due to the scarcity of long-term time series of observed SAT with different observational rules.

Urban-related warming and the corresponding contributions have been generally evaluated using SAT differences between the observation minus reanalysis (OMR) [15] or the SAT differences between urban and rural meteorological stations (UMR) [16-18], which depend on meteorological station observation data. For the OMR method, errors result from the coarse resolution of both the station-based observation and re-analysis data, for which the spatial resolution might range between 0.75 degree and 2.5 degree and the temporal resolution is usually four times daily. For the UMR method, due to the large spatial heterogeneity in the UHI, the urban-related warming might vary, depending on the stations selected as the urban and rural meteorological stations. With rapid economic development and human activities, rural meteorological stations can be more or less affected $[4,19]$, which implies that a 'real' rural station is difficult to identify. Finding pure rural stations is an even bigger problem in China due to the massive urban development, and these have been overgrown during the past several decades, whereas this is not such a massive problem, for example, in the United States or in Europe. Therefore, SAT data with a fine spatial and temporal resolution will be beneficial to evaluating urban-related warming.

Numerical simulations provide an alternative approach for urbanization climate effect studies [20,21]. Long-term integrations using the Weather Research and Forecasting (WRF) [22] regional climate model with fine-resolution spatio-temporal land use data, which approximately represent urban surface expansion during the past several decades [23,24], were adopted to study the impacts on SAT due to urban surface expansion. To more concisely reproduce urban surface expansion in the model, especially at the city scale, nested simulations were adopted at 30-10-3.3 km resolutions, in which a $3.3 \mathrm{~km}$ resolution was adopted for three city clusters displaying marked urban surface expansion over the past several decades: Beijing-Tianjin-Hebei (BTH), Yangtze River Delta (YRD), and Pearl River Delta (PRD). Two cities (Guangzhou and Shenzhen), closely located within 
the PRD areas over southern China and with similar climatic backgrounds but different degrees of urban-surface-expansion during the past several decades, were chosen to compare the daily mean SAT calculated using different methods. Simulated SAT values were used to study the differences in the long-term time series of daily mean SAT calculated using $T_{4}, T_{x n}$, and $T_{c}$. Then, the impacts of differing SAT records on evaluating urban-related warming over Guangzhou and Shenzhen were investigated. The differences in annual mean SAT, trends, and urban-related warming contributions calculated using $T_{4}, T_{x n}$, and $T_{c}$, both in spatial and long-term times series, are discussed.

\section{Experiments}

The experimental design and data used here are similar to those in [8]; however, the former study concentrated on urban-related warming in Beijing and only the simulated values for eight times daily were adopted in calculating daily mean SAT. Detailed information on the experimental design and data are provided in Sections S1-S3 of the Supplementary Materials.

\subsection{Data}

The numerical experiments were driven by the National Centers for Environmental Prediction (NCEP) — the Department of Energy (DOE) Atmospheric Model Intercomparison Project (AMIP-II) reanalysis data (1979-2016) [25]. Annual land use data from 1980 to 2016 were reconstructed based on five satellite-retrieved images from 1980, 1990, 2000, 2010, and 2016 [23,24], which represent urban surface expansion during the last 37 years. The two datasets used here are similar to those in [8].

\subsection{Experimental Design}

Based on previous results, daily mean SAT values calculated using different methods were compared and their impacts on urban-related warming evaluations explored. This analysis remedies the scarcity of observed spatio-temporal meteorological station-based data and provides a basis for climate change studies.

The simulated domain covers most of East Asia with a $30 \mathrm{~km}$ resolution (D1). As urban-surface-expansion is mainly located over eastern China, accompanying rapid economic development, the first nested domain covers most of eastern China (D2). The three second-nested-domains cover three city clusters (D3: BTH, D4: YRD, and D5: PRD) displaying the largest proportion of gross domestic product and intense human activity. The terrain elevation over the simulated domain, the PRD region (including Guangzhou and Shenzhen city), and two cities are displayed in Figure 1a-d.

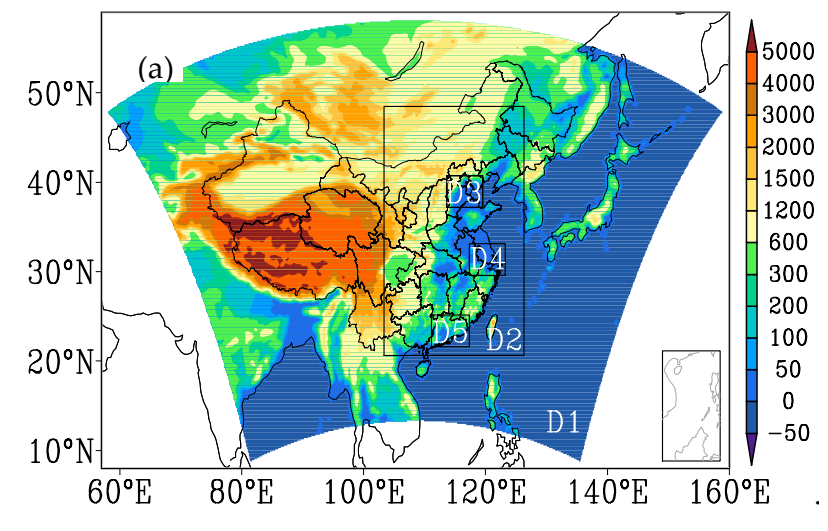

Figure 1. Cont. 

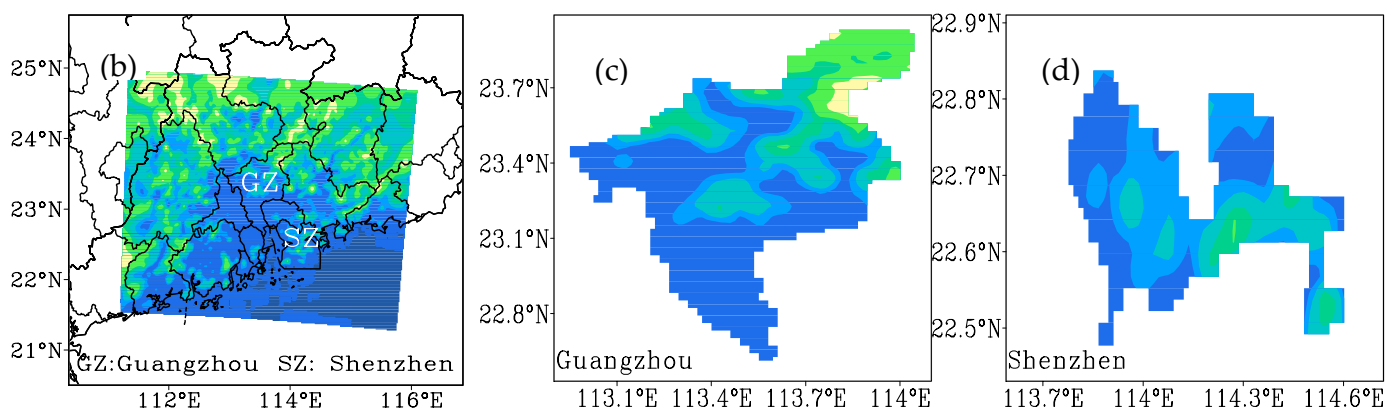

Figure 1. (a) Model domain and (b-d) terrain height distributions over (a) the simulated domain (D1), (b) PRD (D5), and (c) Guangzhou and (d) Shenzhen cities (units: m).

Two numerical experiments, which share similar integrated backgrounds with the exception of land use data (for urban surface distributions only), were performed using the WRF model. The land use data, including urban surface distributions in the 1980s, were used in the first experiment (EX1), whereas annual land use data revealing urban-surface-expansion were adopted in the second experiment (EX2), in which the reconstructed annual land use data from 1980 to 2016 were used. The model was integrated for 18 months for each year individually from 1 July in the previous year and for the whole year in the current year. Then, the simulated results covering the whole period of the current year were analyzed. The impacts of urban-surface-expansion are represented by differences between the simulated results from EX1 and EX2 (EX2 minus EX1). The impacts on urban-related warming are explored in detail using the daily mean SAT calculated using $\mathrm{T}_{4}, \mathrm{~T}_{\mathrm{xn}}$, and $\mathrm{T}_{\mathrm{c}}$.

The experimental design, data, and abbreviations used here are summarized in Table 1. The performance of the model in the SAT simulation has been previously explored and evaluated in $[7,8]$, so is not discussed here.

Table 1. Summary of experimental design, data, and abbreviations used in the integrations.

\begin{tabular}{|c|c|c|c|}
\hline Caption & Numerical Experiments & EX1 & EX2 \\
\hline \multirow[t]{3}{*}{ Experimental Design } & Integration periods & \multicolumn{2}{|c|}{$\begin{array}{l}\text { A series of restarts for individual years starting from } 1 \text { July in the previous } \\
\text { year were performed for the years between } 1980 \text { and } 2016 \text {, for which only the } \\
\text { simulated results for the present year were analyzed. }\end{array}$} \\
\hline & Domains & \multicolumn{2}{|c|}{$\begin{array}{l}\text { The central latitude and longitude of the simulated domain are } 35^{\circ} \text { and } 108.5^{\circ} \\
\text { E. The coarse mesh (D1) covers most of East Asia with a } 30 \mathrm{~km} \text { resolution. } \\
\text { The first nested domain (D2) covers most of eastern China with a } 10 \mathrm{~km} \\
\text { resolution. The second nested domains (D3-D5) cover the three city clusters } \\
\text { (BTH, YRD, PRD) with a } 3.3 \mathrm{~km} \text { resolution. }\end{array}$} \\
\hline & $\begin{array}{l}\text { Physical parameterization } \\
\text { schemes }\end{array}$ & \multicolumn{2}{|c|}{$\begin{array}{l}\text { The unified Noah land-surface model including urban canopy model; the } \\
\text { WRF single-moment } 6 \text { class graupel microphysics scheme; the Community } \\
\text { Atmosphere Model shortwave and longwave radiation schemes; the Yonsei } \\
\text { University boundary-layer scheme; the Grell 3D ensemble cumulus scheme } \\
\text { (for } 30 \text { and } 10 \mathrm{~km} \text { resolution only). }\end{array}$} \\
\hline \multirow[t]{3}{*}{ Abbreviations } & SAT averages & \multicolumn{2}{|c|}{$\begin{array}{l}\mathrm{T}_{\mathrm{xn}} \text { : the averages of } \mathrm{SAT} \text { maximum }\left(\mathrm{T}_{\max }\right) \text { and minimum }\left(\mathrm{T}_{\min }\right) \text { records; } \mathrm{T}_{4} \text { : } \\
\text { the averages calculated using four time records each day; } \mathrm{T}_{\mathrm{c}} \text { : the averages } \\
\text { calculated using the } 24 \text {-h continuous records. }\end{array}$} \\
\hline & $\mathrm{U} 2 \mathrm{U}$ & Urban surface & Urban surface \\
\hline & $\mathrm{N} 2 \mathrm{U}$ & Non-urban surface & Urban surface \\
\hline
\end{tabular}




\section{Results}

\subsection{Urban Surface Expansion over Guangzhou and Shenzhen}

Five satellite-detrieved images displaying the urban surface distributuion for the years between 1980 and 2016 over Guangzhou and Shenzhen are shown in Figure 2.

For Guangzhou, terrain height is high in the northeast and low in the southwest (Figure 1c). Urban surfaces were only located in metropolitan areas over the southwestern part in 1980, whereas forests occupied the majority of areas of the northeastern part. Urban surface expansion mainly occurred over the southwestern part from 1980 to 2016.

For Shenzhen, terrain height is high in the southeast and low in the northwest (Figure 1d). No urban grid cell was detected because it was a small village in 1980. However, urban grid cells increased considerably due to rapid urban surface expansion across the entire area, with the exception of the southeastern part, for which it was mostly covered by forests.

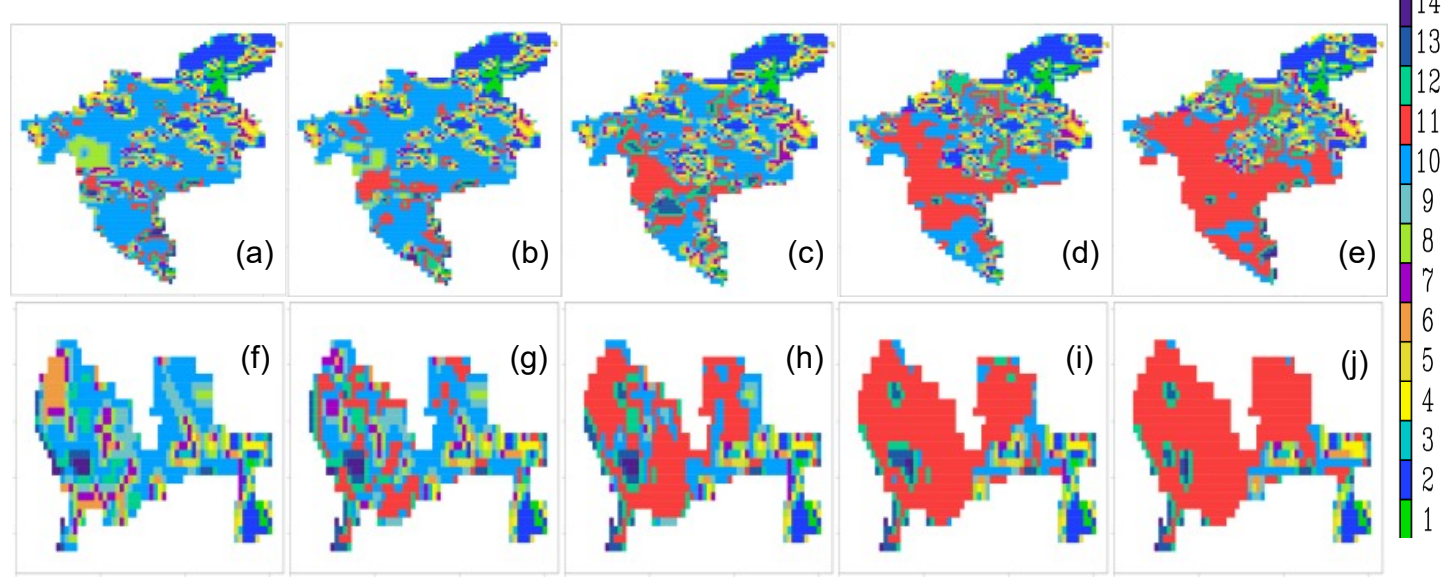

Figure 2. Spatial distributions of different land-use categories in (a-e) Guangzhou and $(\mathbf{f}-\mathbf{j})$ Shenzhen in the years of $(\mathbf{a}, \mathbf{f})$ 1980, (b,g) 1990, (c,h) 2000, (d,i) 2010, and (e,j) 2016, where red denotes urban surface grid cells. Land use categories are: (1) evergreen needleleaf forest, (2) evergreen broadleaf forest, (3) deciduous broadleaf forest, (4) mixed forests, (5) closed shrublands, (6) open shrublands, (7) woody savannas, (8) grasslands, (9) permanent wetlands, (10) croplands, (11) urban and built-up areas, (12) cropland/natural vegetation mosaic, (13) barren or sparsely vegetated areas, and (14) water. Source: [26].

\subsection{Spatial Differences and Trends in Annual Mean SAT}

Annual mean SAT, differing trends under EX1 and EX2, and corresponding differences (EX2 minus EX1) calculated using different methods $\left(\mathrm{T}_{4}, \mathrm{~T}_{\mathrm{xn}}\right.$, and $\left.\mathrm{T}_{\mathrm{C}}\right)$ for 1980 and 2016 over Guangzhou/Shenzhen show similar spatial distributions (Figures 3-6 and Figures S1-S4). Among these results, the values calculated using $\mathrm{T}_{4}$ and $\mathrm{T}_{\mathrm{C}}$ are closer. The weak differences between the values calculated using $\mathrm{T}_{\mathrm{C}}$ and $\mathrm{T}_{4}\left(\mathrm{~T}_{4}\right.$ minus $\mathrm{T}_{\mathrm{c}}$ ) are clearly shown in Figures S1-S4. The differences in annual mean SAT between $\mathrm{T}_{\mathrm{C}}$ and $\mathrm{T}_{4}$ under EX1 and EX2, and the warming differences between EX1 and EX2, as well as the corresponding values for the trends under EX1 and EX2, and the differences for the urban-related warming contributions between EX1 and EX2, do not pass the $90 \%$ confidence level significance $t$-tests. Therefore, only the annual mean SAT, the trends calculated using $\mathrm{T}_{4}$ and $\mathrm{T}_{\mathrm{xn}}$ for 1980 and 2016, and their corresponding differences are discussed in detail.

\subsubsection{Annual Mean SAT}

Spatial distributions of annual mean SAT under EX1 (Figures 3a and 4a) and EX2 (Figures 3b and 4b) for 1980 and 2016 and the warming between EX1 and EX2 (Figures 3c and 4c) calculated using 
$\mathrm{T}_{4}$ are similar to those calculated using $\mathrm{T}_{\mathrm{xn}}$ (Figures $3 \mathrm{~d}-\mathrm{f}$ and $4 \mathrm{~d}-\mathrm{f}$ ) over both Guangzhou (Figure 3 ) and Shenzhen (Figure 4). Of these, only the warming mainly located over the southwestern part of Guangzhou passes the $90 \%$ confidence level significance $t$-tests (Figure 3c,f), whereas the warming occurs across nearly the entire Shenzhen area (Figure 4c,f), excluding the areas over the southeastern past of Shenzhen. Annual mean SAT values calculated using $T_{x n}$ are larger than those calculated using $\mathrm{T}_{4}\left(\mathrm{~T}_{\mathrm{xn}}\right.$ minus $\left.\mathrm{T}_{4}\right)$ under EX1 (Figures $3 \mathrm{~g}$ and $4 \mathrm{~g}$ ) and EX2 (Figures $3 \mathrm{~h}$ and $4 \mathrm{~h}$ ) across the entire Guangzhou (Figure $3 \mathrm{~g}-\mathrm{h}$ ) and Shenzhen (Figure $4 \mathrm{~g}-\mathrm{h}$ ) areas, excluding the northwestern areas under EX2 over Shenzhen. In comparison, the 37-year averaged warming calculated using $\mathrm{T}_{4}$ is weaker than that calculated using $T_{x n}$ over Guangzhou (Figure 3i) and Shenzhen (Figure 4i), excluding over the middle-northern areas of Shenzhen, whereas significant differences only appear in southeastern and northwestern Guangzhou.
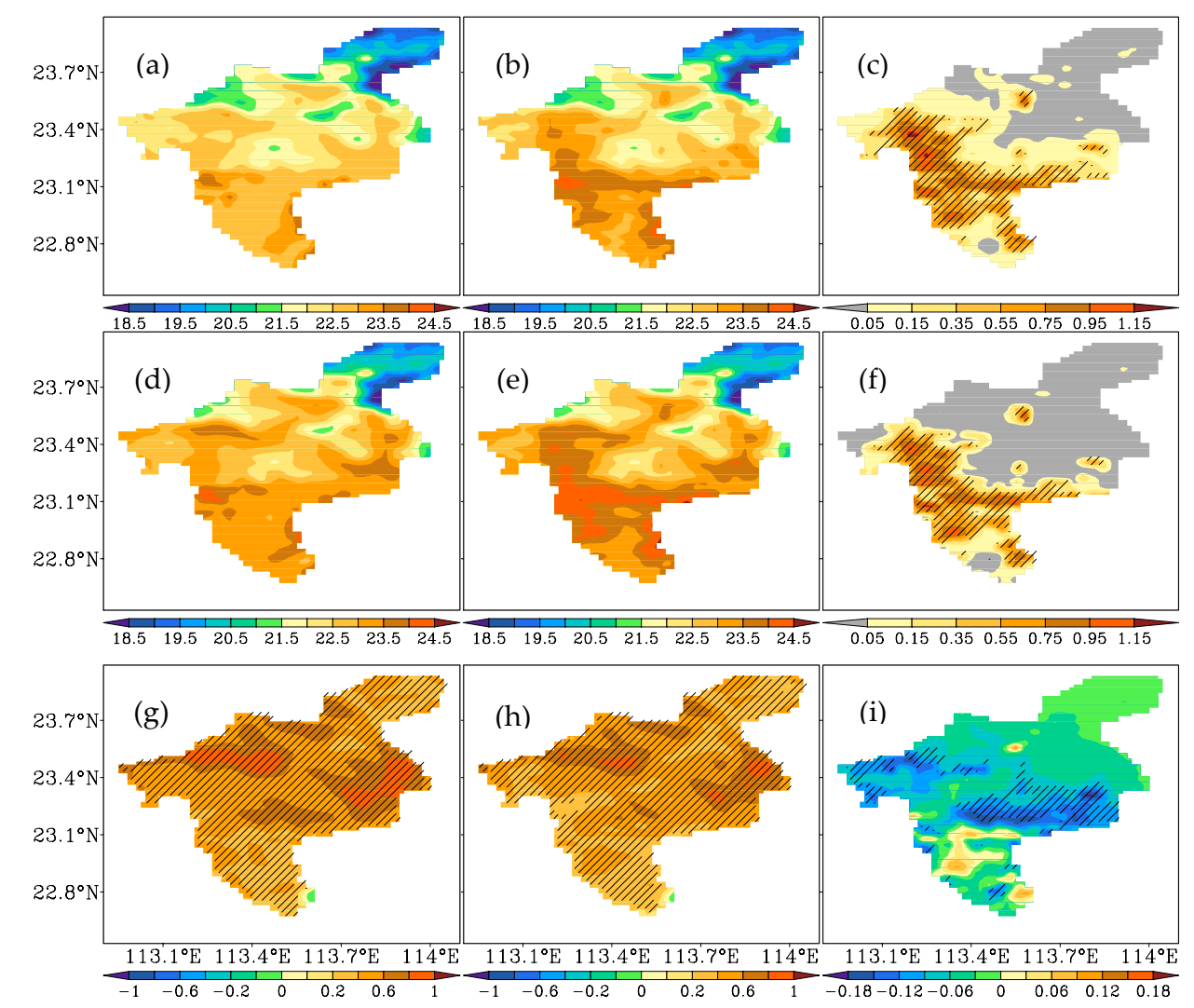

Figure 3. Spatial distributions of $(\mathbf{a}, \mathbf{b}) \mathrm{T}_{4}$ and $(\mathbf{d}, \mathbf{e}) \mathrm{T}_{\mathrm{xn}}$, and $(\mathbf{g}, \mathbf{h})$ the corresponding differences $\left(\mathrm{T}_{\mathrm{xn}}\right.$ minus $\left.\mathrm{T}_{4}\right)$ under $(\mathbf{a}, \mathbf{d}, \mathbf{g})$ EX1 and (b,e,h) EX2 for 1980 and 2016. (c,f) The 37-year averaged warming for (c) $\mathrm{T}_{4}$ and (f) $\mathrm{T}_{\mathrm{xn}}$, and (i) the corresponding differences over Guangzhou (oblique line denotes passing the $90 \%$ confidence level significance $t$-tests, units: ${ }^{\circ} \mathrm{C}$ ).

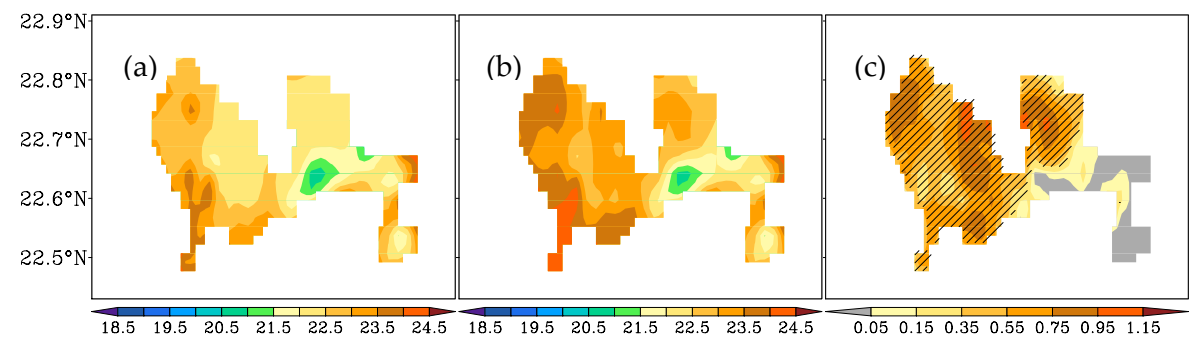

Figure 4. Cont. 

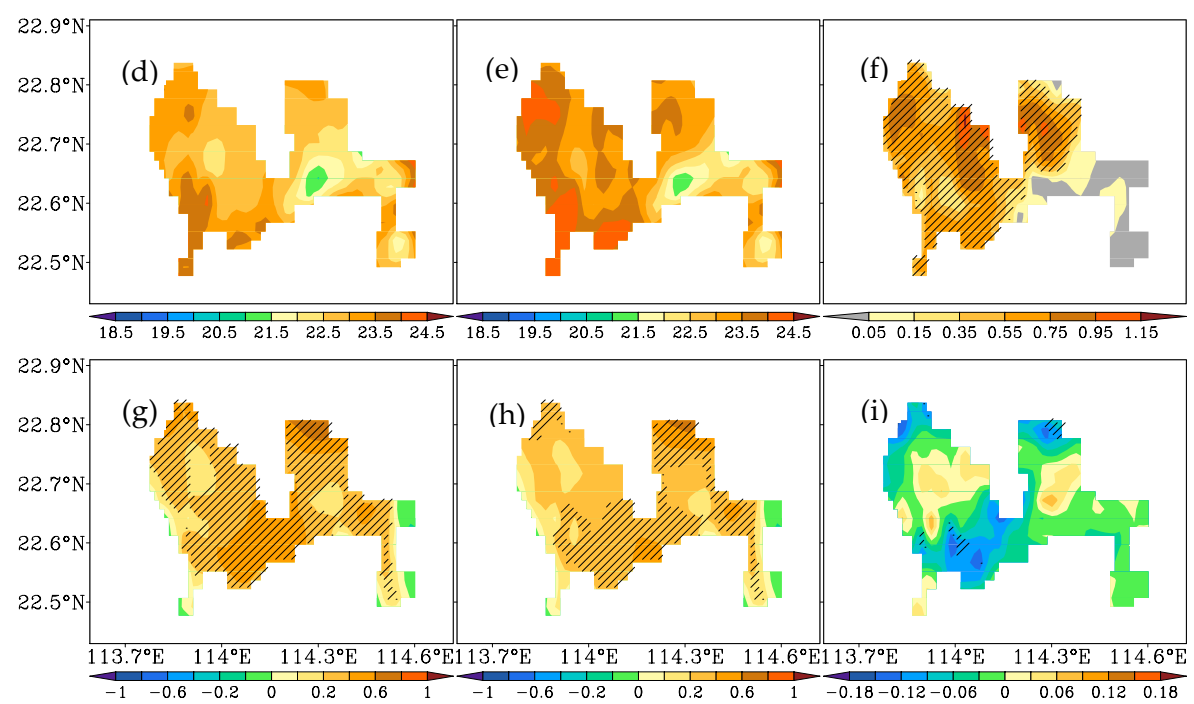

Figure 4. Spatial distributions of $(\mathbf{a}, \mathbf{b}) \mathrm{T}_{4}$ and $(\mathbf{d}, \mathrm{e}) \mathrm{T}_{\mathrm{xn}}$, and $(\mathbf{g}, \mathbf{h})$ the corresponding differences $\left(\mathrm{T}_{\mathrm{xn}}\right.$ minus $\mathrm{T}_{4}$ ) under (a,d,g) EX1 and (b,e,h) EX2 for 1980 and 2016. (c,f) The 37-year averaged warming for (c) $\mathrm{T}_{4}$ and (f) $\mathrm{T}_{\mathrm{xn}}$, and (i) the corresponding differences over Shenzhen (oblique line denotes passing the $90 \%$ confidence level significance t-tests, units: ${ }^{\circ} \mathrm{C}$ ).

\subsubsection{Trends in Annual Mean SAT}

Spatial distributions of the trends under EX1 (Figures 5a and 6a) and EX2 (Figures 5b and 6b) for 1980 and 2016, and the urban-related warming contributions between EX1 and EX2 (Figures 5c and $6 c$ ) calculated using $T_{4}$, are similar to those calculated using $T_{x n}$ (Figures $5 d-f$ and $6 d-f$ ) over both Guangzhou (Figure 5) and Shenzhen (Figure 6). The urban-related warming is mainly located over southwestern Guangzhou (passing the $90 \%$ confidence level significance $t$-tests, Figure $5 \mathrm{c}, \mathrm{f}$ ), whereas the urban-related warming covers the entirety of Shenzhen, excluding the southeastern part (Figure $6 \mathrm{c}, \mathrm{f})$. The trends calculated using $\mathrm{T}_{\mathrm{xn}}$ are generally smaller than those calculated using $\mathrm{T}_{4}$ across the entire Guangzhou (Figure 5g-h) and Shenzhen (Figure $6 \mathrm{~g}-\mathrm{h}$ ) areas under EX1 (Figures $5 \mathrm{~g}$ and $6 \mathrm{~g}$ ), excluding areas in northeastern Guangzhou, and EX2 (Figures $5 \mathrm{~h}$ and $6 \mathrm{~h}$ ), excluding middle-northern areas of Shenzhen. The urban-related warming contributions calculated using $\mathrm{T}_{\mathrm{xn}}$ are generally weaker than those calculated using $\mathrm{T}_{4}$ over both Guangzhou (Figure 5i) and Shenzhen (Figure 6i), excluding the middle-northern areas over Shenzhen.
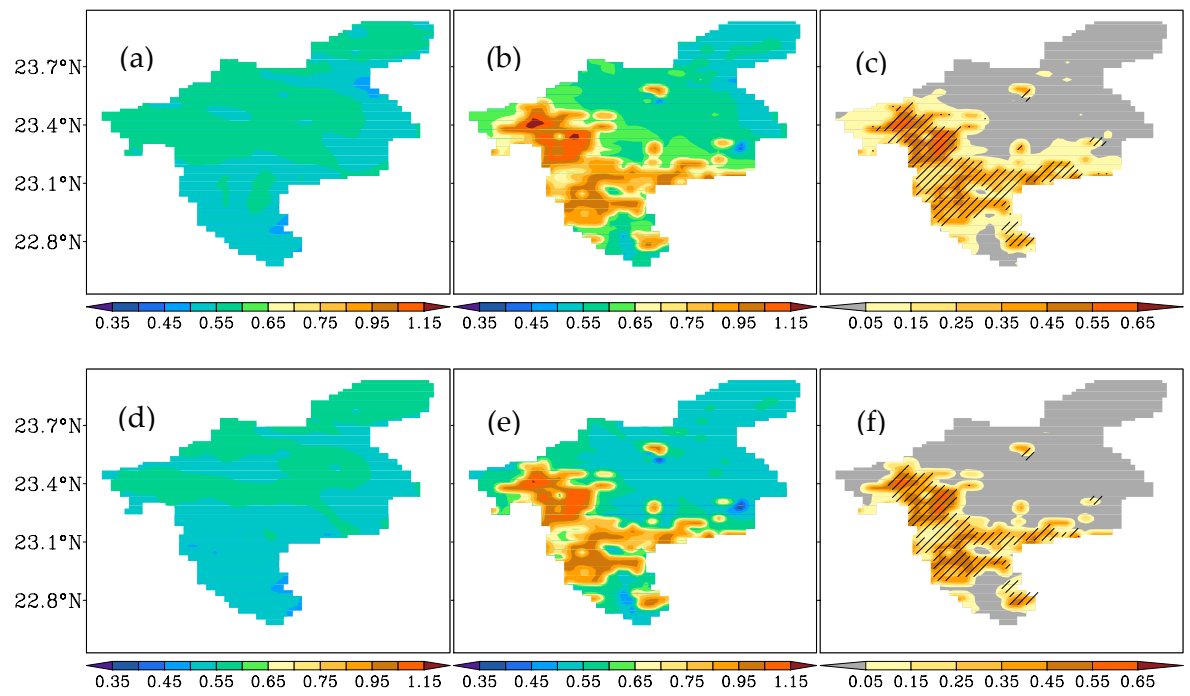

Figure 5. Cont. 


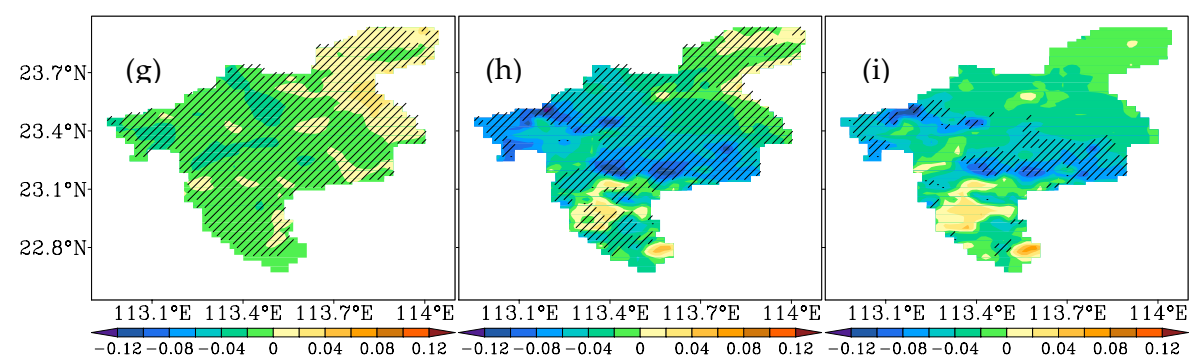

Figure 5. Trends in (a,b) $T_{4}$ and $(\mathbf{d}, \mathbf{e}) \mathrm{T}_{\mathrm{xn}}$, and $(\mathbf{g}, \mathbf{h})$ the corresponding differences $\left(\mathrm{T}_{\mathrm{xn}}\right.$ minus $\left.\mathrm{T}_{4}\right)$ under $(\mathbf{a}, \mathbf{d}, \mathbf{g})$ EX1 and (b,e,h) EX2 for 1980 and 2016. (c,f) The urban-related warming contributions for (c) $\mathrm{T}_{4}$ and (f) $\mathrm{T}_{\mathrm{xn}}$, and (i) the corresponding differences over Guangzhou (oblique line denotes passing the $90 \%$ confidence level significance $t$-tests, units: ${ }^{\circ} \mathrm{C} /$ decade).

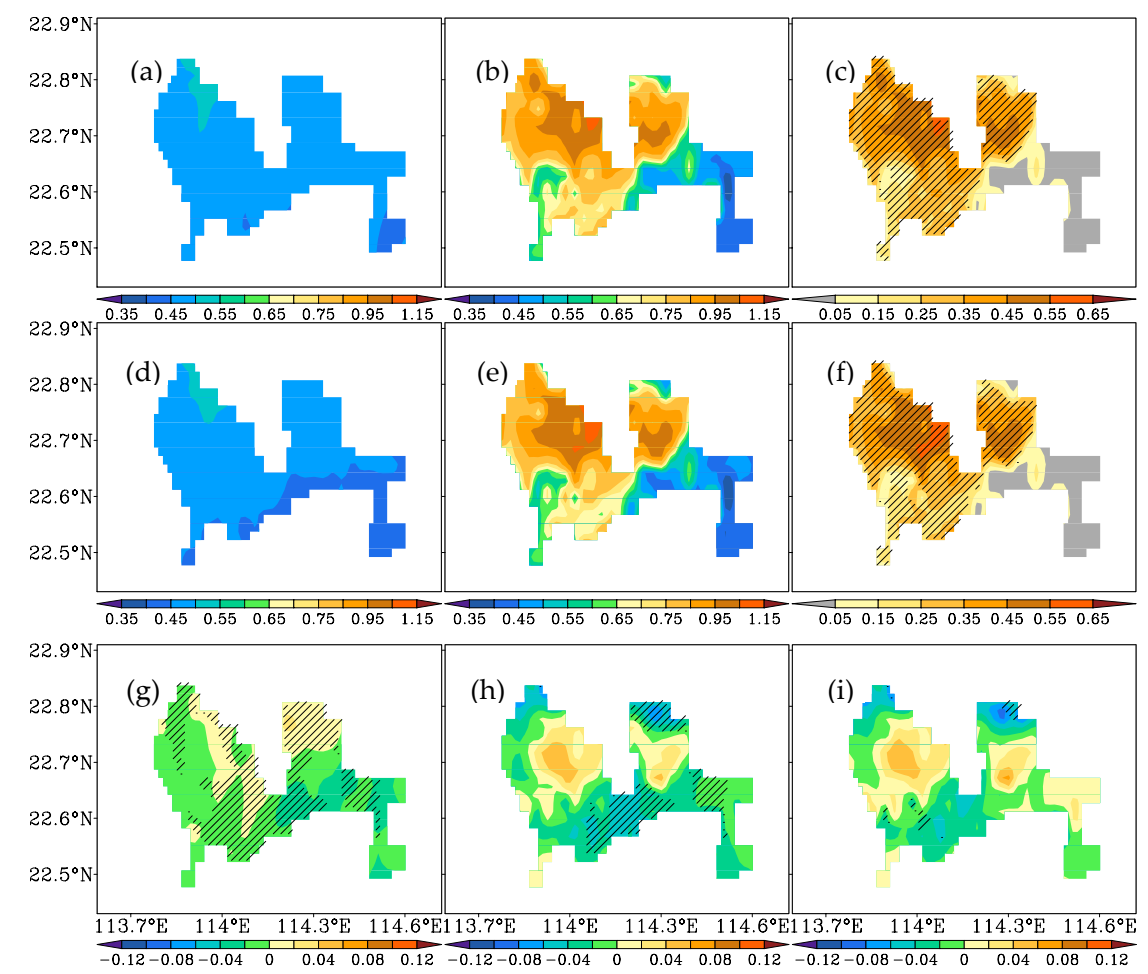

Figure 6. Trends in $(\mathbf{a}, \mathbf{b}) \mathrm{T}_{4}$ and $(\mathbf{d}, \mathbf{e}) \mathrm{T}_{\mathrm{xn}}$, and $(\mathbf{g}, \mathbf{h})$ the corresponding differences $\left(\mathrm{T}_{\mathrm{xn}}\right.$ minus $\left.\mathrm{T}_{4}\right)$ under $(\mathbf{a}, \mathbf{d}, \mathbf{g})$ EX1 and (b,e,h) EX2 for 1980 and 2016. (c,f) The urban-related warming contributions for (c) $\mathrm{T}_{4}$ and (f) $\mathrm{T}_{\mathrm{xn}}$, and (i) the corresponding differences over Shenzhen (oblique line denotes passing the $90 \%$ confidence level significance $t$-tests, units: ${ }^{\circ} \mathrm{C} /$ decade).

\subsection{Time Series Differences in Annual Mean SAT and Trends}

\subsubsection{Annual Mean SAT}

Differences in annual mean SAT calculated using $\mathrm{T}_{4}, \mathrm{~T}_{\mathrm{xn}}$, and $\mathrm{T}_{\mathrm{c}}$ under EX1 and EX2, and the warming differences over subregions of Guangzhou and Shenzhen, are provided in Table 2. Differences in 37-year annual mean SAT calculated using $\mathrm{T}_{4}$ and $\mathrm{T}_{\mathrm{xn}}$ that run between $0.41 \sim 0.53{ }^{\circ} \mathrm{C}$ under EX1 and EX2 over the subregions of Guangzhou (the entire, U2U, N2U, and urban areas), and between $0.29 \sim 0.34{ }^{\circ} \mathrm{C}$ under EX1 and EX2 over the subregions of Shenzhen (the entire and urban areas), generally pass the $99 \%$ confidence level significance $t$-tests. The exceptions are over the N2U areas of Guangzhou under EX2 and the entire areas of Shenzhen under EX2 (passing the 95\% confidence level significance $t$-tests). The corresponding differences calculated using $\mathrm{T}_{\mathrm{c}}$ and $\mathrm{T}_{4}$ are quite small (only 
passing the $80 \%$ confidence level significance $t$-tests over the U2U areas of Guangzhou under EX1). The warming differences calculated using $\mathrm{T}_{4}$ and $\mathrm{T}_{\mathrm{xn}}, \mathrm{T}_{\mathrm{C}}$, and $\mathrm{T}_{4}$ were also quite small.

Table 2. The differences in 37-year annual mean SAT calculated using $\mathrm{T}_{4}, \mathrm{~T}_{\mathrm{xn}}$, and $\mathrm{T}_{\mathrm{c}}$ under EX1 and EX2, and the corresponding differences (EX2 minus EX1) over the subregions of Guangzhou (the entire, U2U, N2U, and urban areas) and Shenzhen (the entire and urban areas).

\begin{tabular}{|c|c|c|c|c|c|}
\hline & & \multicolumn{2}{|c|}{$T_{x n}$ minus $T_{4}$} & \multicolumn{2}{|c|}{$T_{4}$ minus $T_{c}$} \\
\hline & & EX1/EX2 & Difference & EX1/EX2 & Difference \\
\hline \multirow{4}{*}{ Guangzhou } & Entire & $0.53^{* * * *} / 0.48^{* * * *}$ & -0.052 & $-0.071 /-0.093$ & -0.022 \\
\hline & $\mathrm{U} 2 \mathrm{U}$ & $0.51^{* * * *} / 0.41^{* * * *}$ & -0.092 & $-0.14 * /-0.13$ & 0.018 \\
\hline & N2U & $0.48^{* * * *} / 0.42^{* * *}$ & -0.053 & $-0.075 /-0.11$ & -0.033 \\
\hline & Urban & $0.49^{* * * *} / 0.42^{* * * *}$ & -0.072 & $-0.063 /-0.11$ & -0.042 \\
\hline \multirow{2}{*}{ Shenzhen } & Entire & $0.33^{* * * *} / 0.29^{* * *}$ & -0.034 & $-0.053 /-0.086$ & -0.033 \\
\hline & Urban & $0.34^{* * * *} / 0.30^{* * * *}$ & -0.035 & $-0.062 /-0.097$ & -0.035 \\
\hline
\end{tabular}

$* * * * *$ and ${ }^{* * * *}$ denote passing the 80,95 , and $99 \%$ confidence level significance $t$-tests, respectively. Units: ${ }^{\circ} \mathrm{C}$.

\subsubsection{Trends in Annual Mean SAT}

The trends in annual mean SAT calculated using $\mathrm{T}_{4}, \mathrm{~T}_{\mathrm{xn}}$, and $\mathrm{T}_{\mathrm{c}}$ for EX1 and EX2, and the urban-related warming contributions over the subregions of Guangzhou and Shenzhen, are provided in Table 3. The urban-related warming contributions calculated using $T_{4}, T_{x n}$, and $T_{c}$ generally pass the $99 \%$ confidence level significance $t$-tests over the N2U and urban areas of Guangzhou and the entire (excluding using $\mathrm{T}_{\mathrm{xn}}$ ) and urban areas of Shenzhen. In comparison, the urban-related warming contributions only pass the $95 \%$ confidence level significance $t$-tests over the U2U areas of Guangzhou (excluding using $\mathrm{T}_{\mathrm{xn}}$ ) or $80 \%$ confidence level significance $t$-tests over the entire and $\mathrm{U} 2 \mathrm{U}$ ( $\mathrm{T}_{\mathrm{xn}}$ only) areas of Guangzhou. The differences over the U2U areas are largest over different subregions of Guangzhou.

Table 3. Trends (units: ${ }^{\circ} \mathrm{C} /$ decade) in annual mean SAT calculated using $\mathrm{T}_{4}, \mathrm{~T}_{\mathrm{xn}}$, and $\mathrm{T}_{\mathrm{C}}$ for $\mathrm{EX} 1$ and EX2, and the urban-related warming contributions (units: \%) over the subregions of Guangzhou (the entire, U2U, N2U, and urban areas) and Shenzhen (the entire and urban areas).

\begin{tabular}{rcccccc}
\hline & \multicolumn{2}{c}{$\mathbf{T}_{\mathbf{4}}$} & \multicolumn{2}{c}{$\mathbf{T}_{\mathbf{x n}}$} & \multicolumn{2}{c}{$\mathbf{T}_{\mathbf{c}}$} \\
\cline { 2 - 7 } & EX1/EX2 & Contribution & EX1/EX2 & Contribution & EX1/EX2 & Contribution \\
\cline { 2 - 7 } Guangzhou & Entire & $17.7^{*}$ & $0.55 / 0.64$ & $14.0^{*}$ & $0.56 / 0.67$ & $16.7^{*}$ \\
\cline { 2 - 7 } & U2U & $25.3^{* * *}$ & $0.52 / 0.65$ & $19.6^{*}$ & $0.53 / 0.68$ & $22.2^{* * *}$ \\
\cline { 2 - 7 } & N2U & $42.9^{* * *}$ & $0.54 / 0.94$ & $42.5^{* * * *}$ & $0.56 / 0.98$ & $43.5^{* * * *}$ \\
\hline \multirow{2}{*}{ Shenzhen } & Urban & $42.3^{* * *}$ & $0.54 / 0.93$ & $41.7^{* * * *}$ & $0.55 / 0.97$ & $42.8^{* * * *}$ \\
\cline { 2 - 7 } & Entire & $35.2^{* * * *}$ & $0.47 / 0.72$ & $34.6^{* * *}$ & $0.48 / 0.74$ & $35.8^{* * * *}$ \\
\hline \multirow{2}{*}{$*^{* * * *}$, and $^{* * * *}$ Urban } & $43.9^{* * * *}$ & $0.48 / 0.84$ & $43.5^{* * * *}$ & $0.480 / 0.87$ & $44.8^{* * * *}$ \\
\hline
\end{tabular}

Trends and Urban-Related Warming Between $\mathrm{T}_{4}, \mathrm{~T}_{\mathrm{xn}}$, and $\mathrm{T}_{\mathrm{c}}$

For the entire and urban areas of Shenzhen, and the N2U and urban areas of Guangzhou, the trends under EX1 calculated using $\mathrm{T}_{4}, \mathrm{~T}_{\mathrm{xn}}$, and $\mathrm{T}_{\mathrm{c}}$ are close, whereas the corresponding values under EX2 calculated using $T_{c}$ are larger than those calculated using $T_{4}$ and $T_{x n}$, which induce the largest values for urban-related warming contributions calculated using $\mathrm{T}_{\mathrm{c}}$. However, the trends under 
EX1 calculated using $T_{4}$ are smaller than those calculated using $T_{c}$ over the entire and U2U areas of Guangzhou. The changing trends under EX2 calculated using $\mathrm{T}_{4}$ are larger than those calculated using $T_{c}$, which results in larger values for the urban-related warming contributions calculated using $T_{4}$.

Comparing the trends and urban-related warming contributions indicates that performances are similar over the N2U and urban areas of Guangzhou, and the entire and urban areas of Shenzhen. The largest trend values are found under both EX1 and EX2 and the urban-related warming contributions calculated using $\mathrm{T}_{\mathrm{c}}$, while the smallest values result from using $\mathrm{T}_{\mathrm{xn}}$. For the entire and U2U areas of Guangzhou, the smallest values for the trends under both EX1 and EX2 and the corresponding urban-related warming contributions appear when calculated using $\mathrm{T}_{\mathrm{xn}}$. However, the trends under EX1 calculated using $\mathrm{T}_{\mathrm{c}}$ are larger than those calculated using $\mathrm{T}_{4}$, whereas the trends under EX2 calculated using $\mathrm{T}_{\mathrm{c}}$ are smaller than those calculated using $\mathrm{T}_{4}$, which results in the largest urban-related warming contributions calculated using $\mathrm{T}_{4}$. The trends and urban-related warming calculated using $\mathrm{T}_{4}$ and $\mathrm{T}_{\mathrm{xn}}$ are discussed in detail in the following.

\section{Comparison of $\mathrm{T}_{4}$ and $\mathrm{T}_{\mathrm{xn}}$ : Trends and Urban-Related Warming}

Trends in annual mean SAT calculated using $\mathrm{T}_{\mathrm{xn}}$ are generally smaller than those calculated using $\mathrm{T}_{4}$ under both EX1 and EX2 over different subregions of Guangzhou/Shenzhen. Urban-related warming contributions calculated using $\mathrm{T}_{\mathrm{xn}}$ are also smaller than those calculated using $\mathrm{T}_{4}$, which is consistent with the negative values for differences in trends under EX1 and EX2 and the differences in urban-related warming contributions calculated using $\mathrm{T}_{4}$ and $\mathrm{T}_{\mathrm{xn}}$ (Figures 5 and 6). The trends under EX1 and EX2 and urban-related warming contributions over the entire/U2U areas and N2U/ urban areas of Guangzhou were close; of these, marked differences are identified between the former and latter. However, the trends under EX1 and EX2 and urban-related warming contributions are close over the entire and urban areas of Shenzhen due to rapid urban surface expansion from a small village to a metropolis (Figure $2 \mathrm{f}-\mathrm{j}$ ). For the results calculated using $\mathrm{T}_{4}$ and $\mathrm{T}_{\mathrm{xn}}$, the evaluated urban-related warming contributions are close over different subregions of Guangzhou and Shenzhen, excluding over the entire and U2U areas of Guangzhou.

Larger differences in urban-related warming contributions over the U2U areas of Guangzhou are further interpreted using the time series of differences in urban-related warming between $\mathrm{T}_{4}$ and $\mathrm{T}_{\mathrm{xn}}$ and the corresponding trends over different subregions of Guangzhou (Figure 7a). Differences are identified in annual mean SAT calculated using $\mathrm{T}_{4}$ and $\mathrm{T}_{\mathrm{xn}}$; however, the largest differences are found over the U2U areas in different subregions of Guangzhou, which indicates that the differences in urban-related warming between $\mathrm{T}_{4}$ and $\mathrm{T}_{\mathrm{xn}}$ over the U2U areas are larger than those over other subregions of Guangzhou, especially during intense urban-surface-expansion periods between 2000 and 2016. Differences are also detected in annual mean SAT calculated using $\mathrm{T}_{4}$ and $\mathrm{T}_{\mathrm{xn}}$ over different subregions of Shenzhen (Figure $7 \mathrm{~b}$ ), whereas the differences over the urban areas are similar to those over the entire areas of Shenzhen for the whole time series.
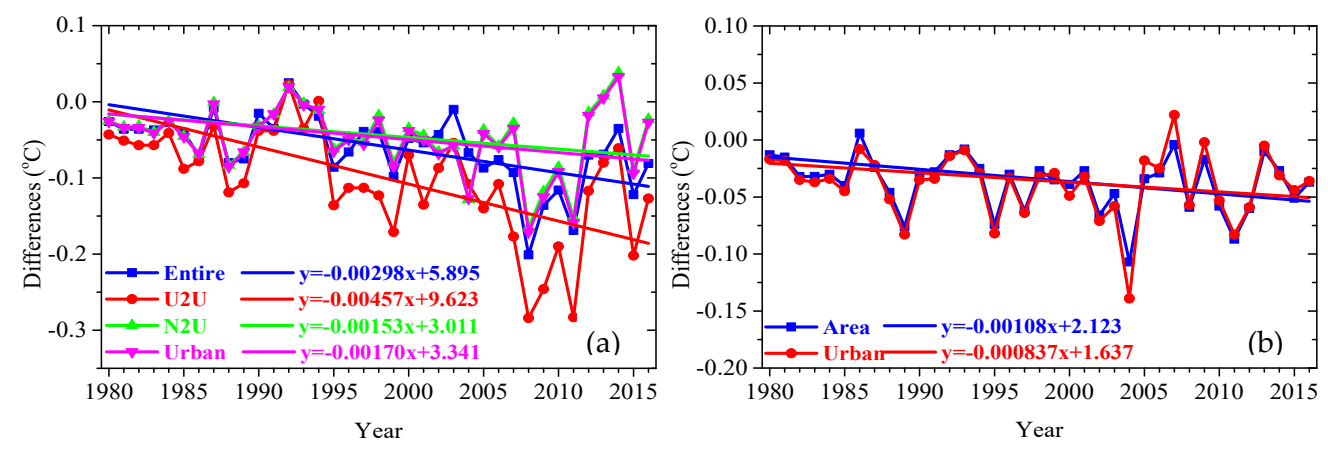

Figure 7. Time series of the differences in urban-related warming between $T_{4}$ and $T_{x n}\left(T_{x n}\right.$ minus $\left.T_{4}\right)$ and the corresponding trends over different subregions (i.e., the whole area, U2U, N2U, and urban areas) of (a) Guangzhou and (b) Shenzhen. 
Notably, the time series of differences in urban-related warming and the corresponding trends over the subregions of Guangzhou and Shenzhen calculated using $\mathrm{T}_{4}$ and $\mathrm{T}_{\mathrm{xn}}$ (Figure 7) display the largest trend $\left(-0.0457^{\circ} \mathrm{C} /\right.$ decade $)$ over the U2U areas of Guangzhou, whereas there are smaller values over subregions of Shenzhen and other subregions of Guangzhou. These results show that the differences in urban-related warming contributions over Guangzhou and Shenzhen with daily mean SAT calculated using different methods are primarily over the U2U areas, whereas the differences are much smaller over areas with urban-surface-expansion influenced areas.

\subsection{Differences in Trends of $T_{\max }$ and $T_{\min }$}

\subsubsection{Comparing Trends for $\mathrm{T}_{\max }$ and $\mathrm{T}_{\min }$}

The trends for $\mathrm{T}_{\max }$ and $\mathrm{T}_{\min }$ under EX1 and EX2, and the corresponding differences for $\mathrm{T}_{\max }$, $\mathrm{T}_{\min }$, and daily temperature range (DTR) over the subregions of Guangzhou/Shenzhen, are shown in Table 4. While the trends in $\mathrm{T}_{\max }$ are larger than those of $\mathrm{T}_{\min }$ under $\mathrm{EX} 1$, the trends in $\mathrm{T}_{\max }$ are smaller than those of $\mathrm{T}_{\text {min }}$ under EX2. These characteristics result in differences between EX1 and EX2 for $\mathrm{T}_{\max }$ that are much smaller than those of $\mathrm{T}_{\min }$, which is expressed by the negative differences for the changing trends of DTR between EX1 and EX2 (figures omitted).

The differences in trends for $\mathrm{T}_{\max }$ between EX1 and EX2 (less than $0.064{ }^{\circ} \mathrm{C} /$ decade) are smaller than those of $\mathrm{T}_{\min }\left(0.18-0.79{ }^{\circ} \mathrm{C} /\right.$ decade) over different subregions of Guangzhou and Shenzhen. The differences in trends for $\mathrm{T}_{\min }$ over the entire and urban areas of Shenzhen are close $(0.51$ and $0.73{ }^{\circ} \mathrm{C} /$ decade, respectively), because the region experienced intense urban surface expansion from a small village with nearly no urban surface in the 1980 s to the present city. In comparison, differences in trends for $\mathrm{T}_{\min }$ over the entire $\left(0.18^{\circ} \mathrm{C} /\right.$ decade $)$ and $\mathrm{U} 2 \mathrm{U}\left(0.23^{\circ} \mathrm{C} /\right.$ decade $)$ areas of Guangzhou were much smaller than those over the corresponding $\mathrm{N} 2 \mathrm{U}\left(0.79^{\circ} \mathrm{C} /\right.$ decade $)$ and urban $\left(0.77^{\circ} \mathrm{C} /\right.$ decade $)$ areas. Marked differences in the trends between entire/U2U and N2U/urban areas are identified and indicate that the impacts of different urban-surface-expansion on the diurnal cycle of SAT might play an important role in the varying trends over different subregions, especially during intense urban-surface-expansion periods.

Table 4. The changing trends of $\mathrm{T}_{\max }$ and $\mathrm{T}_{\min }$ for EX1 and EX2, and the corresponding differences for $T_{\max }, \mathrm{T}_{\min }$, and DTR over the subregions of Guangzhou/Shenzhen (the entire, U2U, N2U, and urban areas).

\begin{tabular}{ccccc}
\hline & & $\begin{array}{c}\mathrm{T}_{\max } \\
\text { EX1/EX2/EX2-EX1 }\end{array}$ & $\begin{array}{c}\mathrm{T}_{\min } \\
\text { EX1/EX2/EX2-EX1 }\end{array}$ & $\begin{array}{c}\text { DTR } \\
\text { EX2-EX1 }\end{array}$ \\
\hline \multirow{3}{*}{ Guangzhou } & Entire & $0.63 / 0.63 / 0.0040$ & $0.47 / 0.65 / 0.18^{* *}$ & $-0.14^{* *}$ \\
\cline { 2 - 5 } & $\mathrm{U} 2 \mathrm{U}$ & $0.58 / 0.61 / 0.029$ & $0.46 / 0.69 / 0.23^{* * *}$ & $-0.17^{* * *}$ \\
\cline { 2 - 5 } & $\mathrm{N} 2 \mathrm{U}$ & $0.59 / 0.60 / 0.0052$ & $0.49 / 1.28 / 0.79^{* * * *}$ & $-0.75^{* * * *}$ \\
\cline { 2 - 5 } & Urban & $0.59 / 0.60 / 0.064$ & $0.49 / 1.26 / 0.77^{* * * *}$ & $-0.72^{* * * *}$ \\
\hline \multirow{2}{*}{ Shenzhen } & Entire & $0.53 / 0.51 /-0.013$ & $0.42 / 0.93 / 0.51^{* * * *}$ & $-0.53^{* * * *}$ \\
\cline { 2 - 5 } & Urban & $0.54 / 0.54 / 0.00056$ & $0.42 / 1.15 / 0.74^{* * * *}$ & $-0.73^{* * * *}$ \\
\hline
\end{tabular}

$* *, * * *$, and ${ }^{* * * *}$ denote passing the 90,95 , and $99 \%$ confidence level significance $t$-tests, respectively. Units:

${ }^{\circ} \mathrm{C} /$ decade.

\subsection{2. $\mathrm{T}_{\max }$ Trends}

The time series of annual mean $\mathrm{T}_{\max }$ under EX1 and EX2 and corresponding trends are shown in Figures S5 and S6. The trends for EX1 are in agreement between different subregions; of which, urban-related warming accounted for $0.64 \%, 4.9 \%, 0.84 \%$, and $-2.5 \%$ over the entire, U2U, N2U, and urban areas of Guangzhou, and $1.2 \%$ and $0.0 \%$ of total warming over the entire and urban areas of Shenzhen, respectively. The contributions were negative and quite small. 


\subsection{3. $\mathrm{T}_{\min }$ Trends}

Time series of annual mean $\mathrm{T}_{\min }$ for EX1 and EX2 and the corresponding trends are shown in Figures S5 and S6. As shown, the trends for EX1 are in agreement between different subregions. The trends for EX2 are much larger over the N2U $\left(1.28^{\circ} \mathrm{C} /\right.$ decade $)$ and urban $\left(1.26^{\circ} \mathrm{C} /\right.$ decade $)$ areas than those over the entire $\left(0.65^{\circ} \mathrm{C} /\right.$ decade $)$ and $\mathrm{U} 2 \mathrm{U}\left(0.69^{\circ} \mathrm{C} /\right.$ decade $)$ areas of Guangzhou. In comparison, the corresponding values over the entire $\left(0.93^{\circ} \mathrm{C} /\right.$ decade $)$ and urban $\left(1.15^{\circ} \mathrm{C} /\right.$ decade $)$ areas of Shenzhen are in better agreement. These distributions contributed to a trend of $0.18 \sim 0.79{ }^{\circ} \mathrm{C} /$ decade over the subregions of Guangzhou and $0.51 \sim 0.73{ }^{\circ} \mathrm{C} /$ decade over the subregions of Shenzhen. Of these, the urban-related warming accounted for $27.2 \%, 32.7 \%, 61.9 \%$, and $55.1 \%$ of total warming for the former, while $61.0 \%$ and $63.8 \%$ of total warming for the latter.

\section{Discussions}

Differences in annual mean SAT and urban-related warming between $\mathrm{T}_{4}$ and $\mathrm{T}_{\mathrm{xn}}$, and the corresponding trends, are further interpreted in Figure 8. The differences in annual mean SAT between $T_{4}$ and $T_{x n}$ under EX1 are generally larger than those under EX2 over different subregions of Guangzhou, among which the values under EX1 and EX2 over the U2U areas are the largest, especially during periods with intense urban-surface-expansion between 2000 and 2016 (Figure 8a). These distributions result in a larger negative value for the trend differences between $T_{4}$ and $T_{x n}$ over the U2U areas. The distances for annual mean SAT differences from $T_{4}$ and $T_{x n}$ between EX1 and EX2 increase due to urban surface expansion, especially over the U2U areas of Guangzhou. The differences in annual mean SAT between $\mathrm{T}_{4}$ and $\mathrm{T}_{\mathrm{xn}}$ under EX1 are close to those under EX2 over different subregions of Shenzhen due to rapid urban surface expansion from a small village to a metropolis (Figure $8 \mathrm{~b}$ ). The differences in annual mean SAT calculated using $\mathrm{T}_{4}$ and $\mathrm{T}_{\mathrm{xn}}$ are attributed to nonlinear or asymmetric variations with time for the diurnal cycle of SAT $[27,28]$. The varied performance in the changes in annual mean SAT over different subregions is further expressed by urban-surface-expansion-induced changes in the diurnal cycle due to the asymmetric warming (Figure 8c,d).
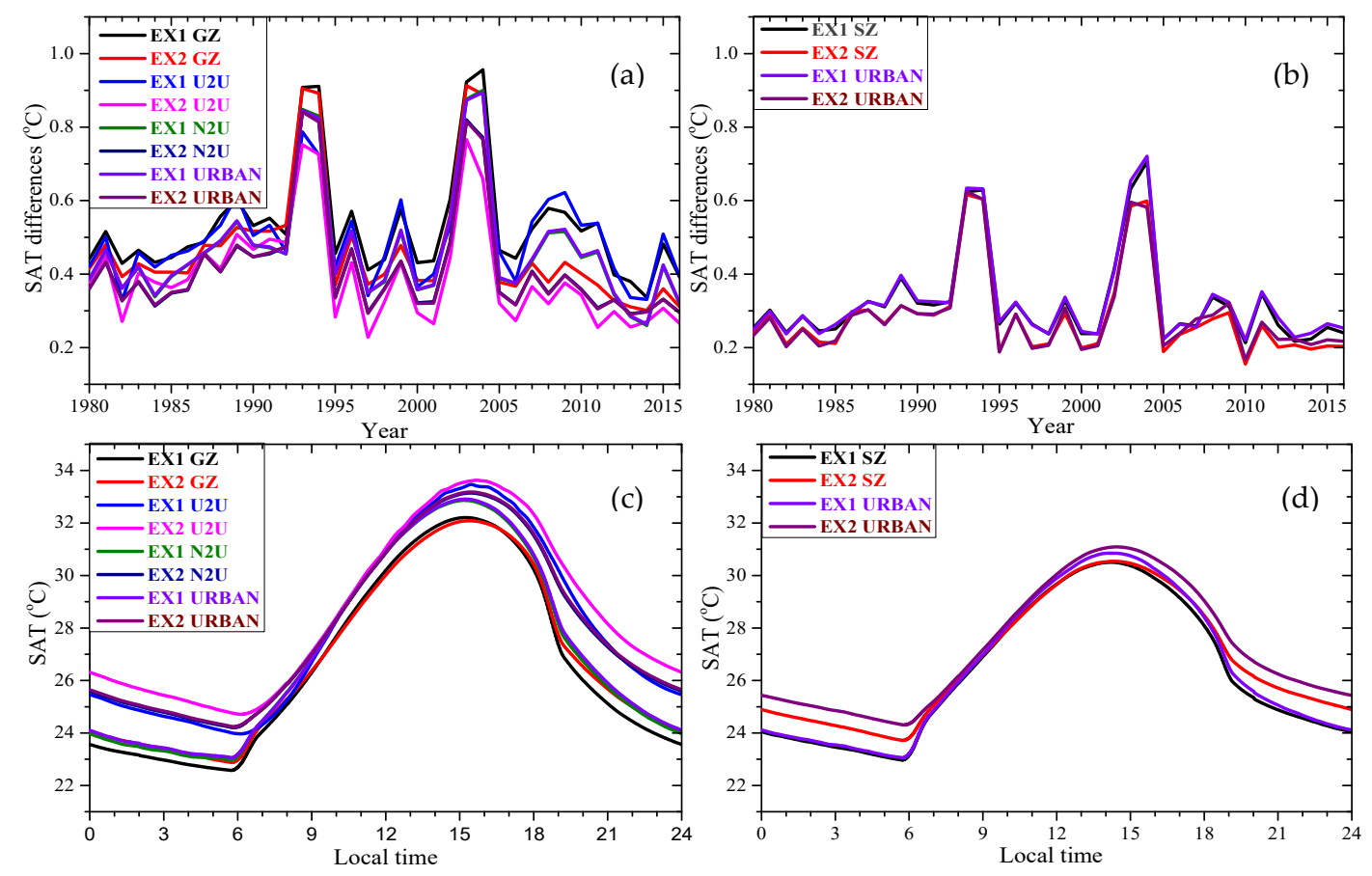

Figure 8. Time series of differences in annual mean SAT under EX1 and EX2 over the subregions of (a) Guangzhou and (b) Shenzhen between $\mathrm{T}_{4}$ and $\mathrm{T}_{\mathrm{xn}}\left(\mathrm{T}_{\mathrm{xn}}\right.$ minus $\left.\mathrm{T}_{4}\right)$. 


\section{Conclusions}

Daily mean SATs calculated using different methods and their impacts on evaluating urban-related warming were explored using the nested WRF regional climate model at a 30-10-3.3 km spatial resolution. The $3.3 \mathrm{~km}$ resolution was adopted for the three city clusters (BTH, YRD, and PRD) over eastern China. Two numerical experiments were performed based on the fixed-in-time land use data in the 1980 (EX1) and reconstructed annual land use data displaying urban surface expansion during 1980 and 2016 (EX2), respectively. Two cities in the PRD area, Guangzhou and Shenzhen, which display different urban-surface-expansion and similar climate contexts, were selected to compare annual mean $\mathrm{SAT}$ and trends calculated using $\mathrm{T}_{4}$ and $\mathrm{T}_{\mathrm{xn}}$ for both spatial distributions and time series.

For the entire areas of Guangzhou and Shenzhen between 1980 and 2016, similar spatial distributions were found for annual mean SAT calculated using different methods. However, the 37-year averaged SAT under EX1 and EX2 calculated using $\mathrm{T}_{\mathrm{xn}}$ was larger than that calculated using $\mathrm{T}_{4}$, for which the differences in annual mean SAT between $\mathrm{T}_{4}$ and $\mathrm{T}_{\mathrm{xn}}$ over the entire and subregions of Guangzhou (between 0.41 and $0.53{ }^{\circ} \mathrm{C}$ ) were larger than those over the entire and urban areas of Shenzhen (between 0.29 and $0.34{ }^{\circ} \mathrm{C}$ ). The 37-year averaged warming calculated using $\mathrm{T}_{\mathrm{xn}}$ was smaller than that calculated using $\mathrm{T}_{4}$ over Guangzhou, whereas the averaged warming calculated using $\mathrm{T}_{\mathrm{xn}}$ was not consistently smaller than that calculated using $\mathrm{T}_{4}$ over Shenzhen. The differences in annual mean SAT calculated using $\mathrm{T}_{4}$ and $\mathrm{T}_{\mathrm{xn}}$ are attributed to nonlinear or asymmetric variations with time for the diurnal cycle of SAT.

The trends of annual mean SAT under EX1 and EX2, and the urban-related warming calculated using $T_{x n}$, were generally smaller than those calculated using $T_{4}$ over the entire areas and subregions of Guangzhou and Shenzhen. Differences in trends between $T_{4}$ and $T_{x n}$ are interpreted as a strong trend for $\mathrm{T}_{\min }$ and a weak one for $\mathrm{T}_{\max }$, which is also shown by the negative differences for the trends of DTR between EX1 and EX2 and then mitigated the trend for $T_{x n}$.

Due to the rapid urban surface expansion, differences in annual mean SAT and urban-related warming contributions between $\mathrm{T}_{4}$ and $\mathrm{T}_{\mathrm{xn}}$ were small over the entire and urban areas of Shenzhen, and the N2U and urban areas of Guangzhou. However, the differences over the entire and U2U areas of Guangzhou were larger, especially for $\mathrm{U} 2 \mathrm{U}$ areas during periods with intense urban surface expansion between 2000 and 2016. The larger differences in annual mean SAT, trends, and urban-related warming over U2U areas of Guangzhou are interpreted as urban-surface-expansion-induced varied changes in the diurnal cycle due to asymmetric warming during the daytime and nighttime over different subregions.

While differences in urban-related warming contributions might be small over Guangzhou and Shenzhen, annual mean SAT and trends calculated using different methods significantly varied, representing an effect that should be studied during future climate change investigations. Furthermore, errors between the observed values and simulated results due to systematic errors from both the model and driving data are sure to impact urban-related warming evaluations. Therefore, more investigations are warranted to address this shortcoming.

Supplementary Materials: The following are available online at http:/ / www.mdpi.com/2073-4433/10/2/48/s1, Figure S1: Spatial distributions of $(\mathrm{a}-\mathrm{c})$ annual mean SAT (units: ${ }^{\circ} \mathrm{C}$ ) and $(\mathrm{d}-\mathrm{f})$ the changing trends (units: ${ }^{\circ} \mathrm{C} /$ decade) calculated using $\mathrm{T}_{\mathrm{c}}$ under $(\mathrm{a}, \mathrm{d}) \mathrm{EX} 1$ and $(\mathrm{b}, \mathrm{e}) \mathrm{EX} 2$, and $(\mathrm{c}, \mathrm{f})$ the corresponding differences $(\mathrm{EX} 2$ minus EX1) over Guangzhou. (Oblique line denotes passing the $90 \%$ confidence level significance $t$-tests), Figure S2: Spatial distributions of $(\mathrm{a}-\mathrm{c})$ annual mean SAT (units: ${ }^{\circ} \mathrm{C}$ ) and $(\mathrm{d}-\mathrm{f})$ the changing trends (units: ${ }^{\circ} \mathrm{C} /$ decade) calculated using $\mathrm{T}_{\mathrm{c}}$ under $(\mathrm{a}, \mathrm{d}) \mathrm{EX} 1$ and $(\mathrm{b}, \mathrm{e}) \mathrm{EX} 2$, and $(\mathrm{c}, \mathrm{f})$ the corresponding differences $(\mathrm{EX} 2$ minus EX1) over Shenzhen. (Oblique line denotes passing the $90 \%$ confidence level significance t-tests), Figure S3: Spatial distributions of the differences for $(\mathrm{a}-\mathrm{c})$ annual mean SAT (units: ${ }^{\circ} \mathrm{C}$ ) and $(\mathrm{d}, \mathrm{f})$ urban-related warming contributions (units: ${ }^{\circ} \mathrm{C} /$ decade) calculated using $\mathrm{T}_{\mathrm{c}}$ and $\mathrm{T}_{4}\left(\mathrm{~T}_{4}\right.$ minus $\mathrm{T}_{\mathrm{c}}$ ) under $(\mathrm{a}, \mathrm{d}) \mathrm{EX} 1,(\mathrm{~b}, \mathrm{e}) \mathrm{EX} 2$, and $(\mathrm{c}, \mathrm{f})$ the corresponding differences (EX2 minus EX1) over Guangzhou. (Oblique line denotes passing the $90 \%$ confidence level significance t-tests), Figure S4: Spatial distributions of the differences for $(\mathrm{a}-\mathrm{c})$ annual mean SAT (units: ${ }^{\circ} \mathrm{C}$ ) and $(\mathrm{d}, \mathrm{f})$ urban-related warming contributions (units: ${ }^{\circ} \mathrm{C} /$ decade) calculated using $\mathrm{T}_{\mathrm{C}}$ and $\mathrm{T}_{4}\left(\mathrm{~T}_{4} \mathrm{minus}_{\mathrm{C}} \mathrm{T}_{\mathrm{c}}\right)$ under $(\mathrm{a}, \mathrm{d}) \mathrm{EX} 1,(\mathrm{~b}, \mathrm{e}) \mathrm{EX} 2$, and $(\mathrm{c}, \mathrm{f})$ the corresponding differences (EX2 minus EX1) over Shenzhen. (Oblique line denotes passing the $90 \%$ confidence level significance t-tests), Figure S5: Time series of annual mean (a,c,e,g) $\mathrm{T}_{\max }$ and $\mathrm{T}_{\mathrm{min}}$, and the changing trends over the subregions of Guangzhou $(\mathrm{a}, \mathrm{b}$ : the entire areas; $\mathrm{c}, \mathrm{d}$ : $\mathrm{U} 2 \mathrm{U}$ areas; $\mathrm{e}, \mathrm{f}$ : 
N2U areas; g,h: urban areas) for EX1 and EX2, Figure S6: Time series of annual mean $(a, c) T_{\max }$ and (b,d) $\mathrm{T}_{\min }$, and trends over different subregions of Shenzhen (a,b: the entire areas, c,d: urban areas) for EX1 and EX2.

Author Contributions: Conceptualization, D.Z; Methodology, D.Z and J.W.; Data curation, D.Z.; Writing-original draft preparation, D.Z.; Writing—review and editing, D.Z and J.W.; Visualization, D.Z.

Funding: This research was funded by the National Key R\&D Program of China under grant no. 2018YFA0606004; the National Natural Science Foundation of China under grant no. 41775087, 41675149, and 41530532; the Chinese Academy of Sciences Strategic Priority Program under grant no. XDA05090206; the National Key Basic Research Program on Global Change under grant no. 2011CB952003; and the Jiangsu Collaborative Innovation Center for Climatic Change. The authors thank the reviewers for their numerous valuable comments to improve the manuscript.

Conflicts of Interest: The authors declare no conflict of interest. The funders had no role in the design of the study; in the collection, analyses, or interpretation of data; in the writing of the manuscript, or in the decision to publish the results.

\section{References}

1. Zhou, B.Z.; Gu, L.H.; Ding, Y.H.; Shao, L.; Wu, Z.M.; Yang, X.S.; Li, C.Z.; Li, Z.C.; Wang, X.M.; Cao, Y.H.; et al. The great 2008 Chinese ice storm: Its socioeconomic-ecological impact and sustainability lessons learned. Bull. Am. Meteorol. Soc. 2011, 92, 47-60. [CrossRef]

2. Qian, X.; Miao, Q.L.; Zhai, P.M.; Chen, Y. Cold-wet spells in mainland China during 1951-2011. Nat. Hazards 2014, 74, 931-946. [CrossRef]

3. Zhao, Y.C.; Zhao, X.F.; Liu, L.L. Spatial pattern analysis on human health risk of heatwave in Xiamen City. J. Geo-Info. Sci. 2016, 18, 1094-1102.

4. Karl, T.R.; Diaz, H.F.; Kukla, G. Urbanization: Its detection and effect in the United States climate record. J. Clim. 1988, 1, 1099-1123. [CrossRef]

5. Arnfield, A.J. Two decades of urban climate research: A review of turbulence, exchanges of energy and water, and the urban heat island. Int. J Climatol. 2003, 23, 1-26. [CrossRef]

6. Ren, G.Y.; Zhou, Y.; Chu, Z.; Zhou, J.; Zhang, A.; Guo, J.; Liu, X. Urbanization effects on observed surface air temperature trends in north China. Nisam sigurna da je ovo dobra skracenica, ali nisam ni nasla drugu 2008, 21, 1333-1348. [CrossRef]

7. Zhao, D.M.; Wu, J. The Influence of urban surface expansion in China on regional climate. J. Clim. 2017, 30, 1061-1080. [CrossRef]

8. Zhao, D.M.; Wu, J. Contribution of urban surface expansion to regional warming in Beijing, China. J. Appl. Meteorol. Climatol. 2017, 56, 1551-1559. [CrossRef]

9. Miller, A.A. Climatology, 8th ed.; Methuen and Co. Ltd.: London, UK, 1953; 318p.

10. Pielke, R.A.; Davey, C.A.; Niyogi, D.; Fall, S.; Steinweg-Woods, J.; Hubbard, K.; Lin, X.; Cai, M.; Lim, Y.K.; $\mathrm{Li}, \mathrm{H}$. Unresolved issues with the assessment of multidecadal global land surface temperature trends. J. Geophys. Res. Atmos. 2007, 112, D16113. [CrossRef]

11. China Meteorological Administration. Specifications for Surface Meteorological Observation Part 6: Measurement of Air Temperature and Humidity; QX/T 50-2007; China Meteorol. Press: Beijing, China, 2007; 14p. (In Chinese)

12. Wang, K.C. Sampling biases in datasets of historical mean air temperature over land. Sci. Rep. 2014, 4, 4637. [CrossRef]

13. Austin, J.F.; McConnell, A. James Six F.R.S. Two Hundred years of the six's self-registering thermometer. Notes Rec. R. Soc. 1980, 35, 49-65.

14. Vose, R.S.; Easterling, D.R.; Gleason, B. Maximum and minimum temperature trends for the globe: an update through 2004. Geophys. Res. Lett. 2005, 32, L23822. [CrossRef]

15. Kalnay, E.; Cai, M. Impact of urbanization and land use change on climate. Nature 2003, 423, 528-531. [CrossRef] [PubMed]

16. Howard, L. Climate of London deduced from meteorological observation. Harvey Darton 1833, 1, 1-24.

17. Duckworth, F.A.; Sandberg, J.S. The effect of cities upon horizontal and vertical temperature gradients. Bull. Am. Meteorol. Soc. 1954, 35, 198-207. [CrossRef]

18. Oke, T.R. Boundary Layer Climate; Great Britain at the University Press: Cambridge, UK, 1987; pp. 1-3.

19. Yan, Z.W.; Wang, J.; Xia, J.J.; Feng, J.M. Review of recent studies of the climatic effects of urbanization in China. Adv. Clim. Change Res. 2016, 7, 154-168. [CrossRef] 
20. Masson, V. Urban surface modeling and the meso-scale impact of cities. Theor. Appl. Climatol. 2006, 84, 35-45. [CrossRef]

21. Ooka, R. Recent development of assessment tools for urban climate and heat island investigation especially based on experience in Japan. Int. J. Climatol. 2007, 27, 1919-1930. [CrossRef]

22. Skamarock, W.C.; Klemp, J.B.; Dudhia, J.; Gill, D.O.; Barker, D.M.; Duda, M.G.; Huang, X.Y.; Wang, W.; Powers, J.G. A Description of the advanced research WRF version 3. NCAR Tech. Note 2008. NCAR/TN-475+STR. [CrossRef]

23. Jia, G.; Xu, R.; Hu, Y.; He, Y. Multi-scale remote sensing estimates of urban fractions and road widths for regional models. Clim. Chang. 2014, 129, 543-554. [CrossRef]

24. Hu, Y.; Jia, G.; Pohl, C.; Feng, Q.; He, Y.; Gao, H.; Xu, R.; van Genderen, J.; Feng, J. Improved monitoring of urbanization processes in China for regional climate impact assessment. Environ. Earth Sci. 2015, 73, 8387-8404. [CrossRef]

25. Kanamitsu, M.; Ebisuzaki, W.; Woollen, J.; Yang, S.-K.; Hnilo, J.J.; Fiorino, M.; Potter, G.L. NCEP-DOE AMIP-II Reanalysis (R-2). Bull. Am. Meteorol. Soc. 2002, 83, 1631-1643. [CrossRef]

26. Zhao, D.M.; Zha, J.L.; Wu, J. Comparisons of urban-related warming for Shenzhen and Guangzhou. Atmos. Ocean. Sci. Lett. 2018, 11, 330-337. [CrossRef]

27. Oke, T.R.; Spronken-Smith, R.A.; Jáuregui, E.; Grimmond, C.S.B. The energy balance of central Mexico City during the dry season. Atmos. Environ. 1999, 33, 3919-3930. [CrossRef]

28. Roth, M.; Oke, T.R.; Emery, W.J. Satellite-derived urban heat islands from three coastal cities and the utilization of such data in urban climatology. Int. J. Remote Sens. 1989, 10, 1699-1720. [CrossRef]

(C) 2019 by the authors. Licensee MDPI, Basel, Switzerland. This article is an open access article distributed under the terms and conditions of the Creative Commons Attribution (CC BY) license (http:/ / creativecommons.org/licenses/by/4.0/). 